\title{
Demand Bubble Management
}

\author{
Margherita Corniani*
}

\begin{abstract}
Demand Bubble is a temporary client aggregation that is caused by the innovative supply configuration issued by a company.

To create demand bubbles companies must have a deep knowledge of their market and their competitors, being able to act and react 'before and better than competitors'.

In instable global markets, demand bubbles are the advanced reply to segmentation limits and a mean to accentuate competitive dynamics.
\end{abstract}

Keywords: Demand Bubbles; Segmentation; Information System; Global Competition

\section{Demand Segmentation and Over-Supply}

The relationship between demand and supply in a market can be considered as an indicator of the competition dynamics acting in the market ${ }^{1}$. Such a relationship can be investigated by referring to extreme situations: at one extreme by the excess of demand with respect to supply $(\mathrm{D}>\mathrm{S})$, and at the other by the presence of greater supply than demand $(S>D)$. Situations of essential equilibrium between supply and demand $(D \approx S)$ are found between these two extremes ${ }^{2}$. These typical competitive situations characterize market conditions with specific distinctive features that are a useful guide to economic and business management analyses.

In particular, in scarcity economies (i.e. excess of demand with respect to supply), the economic environment is characterized by a significant potential market. However, supply is inadequate as manufacturing capacity is not sufficient to satisfy market demand. The material components of products have absolute supremacy as verifiable through objective parameters. Customer needs are indeed elementary, well known and completely stable. Technological innovations are rare and, in any case, the timing and method by which innovations are introduced into the market are independent of competitive strains ${ }^{3}$.

This competitive situation was identified historically in the first half of the last century in the United States, and for a period that includes the sixties in Italy as well.

The focal point of market structure in scarcity economies is supply. Analysis of a sector or market focuses on the analysis of the size of businesses operating in it, on

* Assistant Professor of Management, University of Milan-Bicocca (margherita.corniani@unimib.it) 
market share levels and on the similarities and dissimilarities between their product offerings.

As a competitive situation moves gradually toward an economy characterized by the equilibrium between supply and demand, as observed in many United States markets in the sixties and in many Italian markets at the end of the eighties, the emphasis tends to move to products and the degree to which they can be substituted as a function of sale price. Companies in this phase tend to concentrate on products, which can be differentiated not only on price, but also through tangible and intangible features by means of advertising, choice of distribution channels, etc.

Therefore, economies in which demand and supply are in equilibrium manifest efficient mass production capacity, and organized, aggressive marketing. The range of offering is wide, very differentiated and aimed at the satisfaction of a wide range of expectations by potential customers. This is made possible by the presence of a large number of competitors within the same market, with products characterized by the same basic function and differentiated by features that are accessory but not perceived as marginal by customers.

The consumer-oriented principle came to the fore within this competitive situation, and is the result of evolution in the interpretation of demand structure characteristics. In scarcity economies far from saturation and actually not even fully satisfied by a supply limited by low manufacturing capacity, demand is perceived as the sum of individual people who exhibit homogeneous consumption habits and needs. The focal point of the market is thus represented by supply, which faces demand that is ready to buy anyway.

The concept of segmentation arises instead in economies characterized by dynamic equilibrium between supply and demand, where consumers are recognized as different from one another and where such differences translate into differences in market demand ${ }^{4}$. According to this interpretation, demand is far from homogeneous: on the contrary, it can be split in order to identify the differences amongst potential customers and then regrouped into sets that are separately homogeneous according to the distinctive types deemed relevant by companies. The segmentation process thus creates a series of subsets within market demand: distinct groups of customers which, with respect to certain parameters, are homogenous within each segment and non-homogeneous between different segments.

The fundamental principle behind this process is that consumers differ in their tendency to respond to market stimuli. Therefore, it is useful to attempt to divide them into groups in order to allow companies to obtain homogenous responses within each group, and heterogeneous responses amongst different groups - as a function of the same stimulus.

However, demand segmentation process effectiveness for business management requires segments to be measurable and accessible. The former requirement is met by identifying segments for which size and expected purchases can be assessed quantitatively in advance. The sales potential can thus be assessed quantitatively and dynamic growth over time may be predicted. Measurability also requires the segment to be large enough to justify the investment aimed at attracting such a group of potential customers through specific marketing actions. Instead, accessibility requires that an identified segment is reachable by specific marketing action. A segment that cannot be reached is inaccessible, with a company not being able to 
make the peculiarities of its offering known to members of the segment, and thus cannot succeed in stimulating a purchasing reaction.

A segment, therefore, can be defined as effective and efficient where: it is homogeneous internally and heterogeneous with respect to other segments in terms of varying ability to respond to marketing stimuli, and it is measurable and accessible.

Segmentation is, however, based on a fundamental prerequisite that is needed to activate the demand segmentation process and to obtain economically exploitable segments. It is the buying behaviour stability requirement, which in turn depends on sufficient stability in relation to market dynamics. This requirement is often not made explicit in segmentation processes for two main reasons: first, because it is a pre-condition to segmentation, and second, because segmentation processes originated and evolved in competitive situations with so-called equilibrium between supply and demand. In this case markets are indeed characterized by essential stability within their characteristic dynamics, and thus also for customer buying behaviour. Therefore, any reference to the stability pre-requirement would seem superfluous, since stability is one of the characteristic features of markets.

Thus, the relevance of this pre-condition to segmentation tends to emerge only when the competitive dynamics of markets undermine customer buying behaviour stability, and hence the inherent usefulness of the segmentation process. This is what happens during the transition from an equilibrium supply and demand situation to a so-called 'over-supply economy'.

Indeed, demand is very stratified, with dissimilar needs and expectations that are satisfied according to a complex synthesis of tangible and intangible aspects related to the offering. There is a continuous search for equilibrium between supply and demand, which is 'naturally' unstable as it can be destabilized by the actions and reactions carried out by competitors to alter the choices made by specific market demand segments 5 .

Particularly in over-supplied markets, competition assumes a frenetic pace, associated with accelerated technological innovation and rapid competitive imitation mechanisms. Such competitive conditions can be observed today in a significant number of sectors, and correlate to markets in the advanced maturity phase and markets characterized by the quantitative saturation of demand, that is by sales that cannot be increased even through price reduction. In such contexts, non-basic factors - related to purchase and use and mostly unconnected to material aspects - increase in value. Domains of dominance by intangible aspects related to the offering develop, with the effect of driving the competition in entire market sectors toward new competitive models - unstable and based on intangible factors ${ }^{6}$. In over-supplied markets, competition tends to focus on the time factor (time-based competition), which on the one hand influences the action-reaction process related to the players involved, and on the other hand increases demand dynamism. The main effect of this dynamism is a direct attack on the basis of the market demand segmentation process, in which segment stability, and hence the potential use of segments by companies, are weakened.

The 'crisis' in demand segmentation methods based on the behaviour stability hypothesis is thus determined by endemic instability factors, introduced and managed by companies with action aimed at ensuring a response consistent with their own offering - in short, aimed at the creation and exploitation of 'demand bubbles'. 


\section{Demand Bubbles}

Demand bubbles identify temporary groups of purchasers, held together by a shared interest in the specific features of an offering from a certain company. Demand bubbles arise therefore from a specific, planned company stimulus (typically an offering that features tangible and intangible aspects that are able to sway purchasing preferences in a group of potential customers). This thereby allows for the fast pooling of a sizable number of purchasers that are homogeneous in their interest regarding the company's offering. Once the product or service has been bought, the bubble tends to disappear, as group members are not interested in further purchases similar to the one made. Once all the people who share an interest in the offering have responded positively by purchasing and have been satisfied, the company must change its offering and search for a new group to attract - by stimulating their interest and satisfying their needs.

Demand bubbles and demand segments are thus specific parts of overall market demand that allow companies to split and focus their marketing efforts on welldefined objectives. Segments and bubbles can be identified through specific variables and can be described based on specific criteria - necessary to select and adopt suitable marketing strategies.

Bubbles are the outcome of demand aggregation processes developed by companies to reduce market complexity. Markets are extremely non-homogeneous, especially in situations of over-supply and heavy competition. They must be restored to partial homogeneous units to allow for the targeted, controlled use of marketing. In this sense, segments (obtained through splitting processes) and bubbles (derived from aggregation processes) create groups of customers through actions specifically planned by companies. Both segments and bubbles assume an in-depth knowledge of demand in order to derive the variables needed in determining the criteria for splitting overall demand. The parts thus defined (segments or bubbles) can then be qualified by further variables and characteristic quantifiers to obtain the information needed to guide the making and marketing of a company's products/services.

The main difference between segments and bubbles is therefore different stability over time and space regarding the respective groups of purchasers, and, consequently, the different methods used to identify and treat them. In particular, segmentation requires an identified group to maintain sufficient stability to allow the company to continue the manufacturing and marketing of certain products over time. The manufacturing and marketing costs must be justified by repetitive buying behaviour that allows for an adequate return on the investment made.

When market stability fails, the probability of recovering incurred costs tends to decrease, and the segmentation performed can turn out to be useless. The nonhomogeneous nature of markets, however, remains true, and companies must find a way to manage the high level of complexity thus arising - a search for an alternative way that allows for the inclusion of such instability. In this sense, instability must be transformed from an exogenous variable that undermines demand segmentation as implemented by companies, into the focus of company policy for the management of demand, as in the process of bubble creation and management.

In some hardware product markets, like computer printers, an offering that is very competitive from the point of view of product 
performance (for example, number of pages printed per minute, print quality, availability of colour and black and white cartridges, etc.), price and distribution (similar to the competition) can temporarily aggregate groups of purchasers that would have nothing in common except for their interest in certain printer features at certain times. Indeed, the same printer may be the first-buy choice for a student of computer science, an upgrade replacement of a lower performing printer for a small professional firm or the solution adopted for basic billing functions by a large international hotel chain.

Purchasers are grouped because of their high propensity to purchase a specific offering by a company. This group - defined here as a demand bubble - does not identify a segment, since it is active for a limited time span (for example a few months or weeks). The stability prerequisite, essential in creating a segment, ensures highly repetitive behaviour by members of the segment. Hence a company can identify the distinctive features of a segment as a useful guide to the development/manufacturing/marketing of its products. The stability of the elements contributing to segment development (characteristic features, demand propensity, competitive variables, etc.) in any case ensures a certain number of purchasers for a product conceived and made according to certain expectations. The repetitive behaviour ensured by segment stability is, however, absent in a bubble, which thus arises from the ability to identify and aggregate non-repetitive behaviour to be satisfied by an offering that constitutes a temporary solution. The creation of a demand bubble develops on the basis of an unstable situation over space and time in relation to consumer choice - with companies basing their marketing policies precisely on such instability.

A company identifies instability as a characteristic feature of demand and competition dynamics, and acts on both through solutions that it can develop and end within a limited time span. To this end, traditional segmentation and positioning criteria cannot be applied. The logic behind the characteristic processes must be subverted.

Indeed, the segmentation process involves a company identifying several groups of potential customers by means of certain techniques, and describing them so as to adjust its offering through a consistent characterization process. The company is then able to exploit this strategic option over time through a series of actions designed to promote and spread its commercial proposals within the chosen segments.

In the case of demand bubbles, in-depth, continuous information about demand must be available to the company to allow it to structure its offering, which over a very short time span enables the aggregation of sufficient numbers of purchasers to ensure a return on the investment made.

The stability on which segmentation is based gives a company enough time to know demand, formalize the segments in which it can operate, and take its offering to some of them (the target) by first devising a strategy and then making operational choices that derive from it.

In highly competitive over-supplied markets, characteristic instability requires that companies acquire and maintain an in-depth knowledge of demand and operate an adequate network in order to reach customers rapidly. In these markets, therefore, companies exploit instability and make use of the intangible assets 
(company culture, information systems and brand equity) that allow for the development of a time-based competition strategy ${ }^{7}$.

Indeed, a strong, stable brand identity allows a company to manage instability, as this is the centre of stability and security for the company around which the buypreferences for a substantial number of purchasers can coalesce. Similarly, a system of solid relationships with supply, logistic and distribution organizations ensures the operating capacity needed to move fast with a well-defined commercial offering. These brand and relation resources, however, can be activated only if an extensive, flexible and continuous management information system is available to the company. Indeed, the creation of demand bubbles requires continuous activity and significant effort in managing instability. Each bubble needs accurate planning in terms of its characteristic mode and timing. In this sense, in deciding to satisfy the needs of a well-defined bubble, a company must have correctly identified the features of the offering that allow for the aggregation of a sizable group of purchasers, and must also estimate the possible lifetime of the bubble and the required quantities of products/services.

The time factor, as postulated by the concept of time-based competition, is fundamental for demand bubbles in three respects. First, instability (characterizing global over-supplied markets in which demand bubbles develop) is based on the acceleration of many phenomena, resulting from a general compression in company action-reaction times. Second, timing is a key variable in the management of demand bubbles with respect to the choice of appropriate time to propose a given action (time value). Finally, demand bubbles are also defined in terms of time duration, which requires precise planning of the qualitative and quantitative aspects of the offering.

Demand bubble time management thus requires a company information system that facilitates action coordination for the development of knowledge tools regarding market size and trends (demand and competition), and for the ability to manage the financial, manufacturing and logistic flows needed for the implementation of the specific project on which each demand bubble is created, grows and dies. In this context, typical strategic management processes (in the form of analysis with a long-term perspective) and operational management processes (in the form of action with a short-term perspective) ${ }^{8}$, which in stable economies follow one another, are bound to overlap continuously, thus making the distinction between the two aspects complex and subtle, and often useful only at the conceptual level.

The planning of demand bubbles, therefore, moves in synchronization with operational implementation because market instability does not allow for separation of the two stages, and because of competitor action in endeavouring to promote their own bubbles.

\section{The Management of Demand Bubbles}

A demand bubble does not appear spontaneously following a company's commercial offering, but derives from the specific activity of market analysis and design of the offering. The bubble requires targeted action in order to be created together with management (as is also the case for the exploitation of market segments), with processes requiring a complex combination of activities to be performed within specific constraints. In the case of demand bubbles, a company 
must have on hand the information needed to identify the key variables that express the core trends that in turn are needed in order to design the bubble. Bubble economics are in reality determined by bubble size and duration. The company creating it must be able to reach a return and get it over time so as to recover the investment made in bubble creation before competitors can come out with more attractive offers.

A company acts temporarily as a monopoly ${ }^{9}$ within the bubble but such an advantage is short-lived and is certain to be ended by the competition, which is engaged in the same direction.

The management of a bubble therefore requires a company to be able to do two things: identify the features of an offering that will allow it to attract a sufficient number of purchasers while developing temporary barriers to entry by competitors, and, seize the right moment to launch the offering in order to optimally exploit the size of the bubble and the barriers set up.

The setting up of an offering that can give rise to a profitable bubble requires knowledge of market demand and supply dynamics (competition) gained through continuous, fast and targeted means. The information system behind this knowledge must be supported by continuous market surveys that can, in effect, only describe phenomena that have already taken place. Such surveys have been provided by the largest market research companies for some time and are now available in 'real time'. Suitable tools must also be implemented for the monitoring of critical variables that can produce trend indicators. These indicators must be identified in relation to demand and the purchasers' capacity to appreciate one type of offering more than another, and competitors with their timing and modes of intervention in the market (competitive intelligence).

The creation of demand bubbles, in particular, requires a consistent relationship with the market, regarding both final consumers and other partners contributing to the development of such a relationship (trade, media and financial institutions). Indeed, trade, media and financing intermediaries are crucial in over-supplied markets for the development of relationships with the market ${ }^{10}$. In particular, commercial distribution plays a fundamental role, as it is in an intermediate position between a company's offering and final demand, and therefore intervenes in the demand bubble creation and exploitation process. These intermediaries are in direct contact with final demand and act as a node where company offerings are concentrated. They can collect needed information and are in a position to contribute to the development of demand bubbles, undermine them or even create them independently.

The role of trade is crucial for the development of bubbles in over-supplied markets. Companies need information that is easily gathered and controlled by distribution and companies must negotiate several aspects with intermediaries: sale price, retailer-based promotions, display mode for the company's offering, timing and location of sales activity and the entire implementation of the conditions that allow for demand bubble generation. Distribution can thus assume an active role in the demand bubble creation process and become the crucial link in creating the conditions for the bubble to develop -by encouraging or obstructing company action (possibly with its own actions or through private labels).

The demand bubble management process requires companies to have the necessary ability, prior to starting a bubble, to design, promote, maintain and 'burst' a bubble. Such abilities can be activated as long as a significant knowledge relationship with the market has already been established, and the necessary 
distribution and supply relationships are available - all needed in order to plan the means and timing of the offering.

In relation to a knowledge relationship with the market, companies endowed with significant brand equity have the necessary qualifications to promote a temporary offering that can attract large numbers of customers over a very short time. The trust associated with a brand can indeed leverage on a company being well known when it makes an offering, thus facilitating the reaching out to customers. At the same time, this condition requires companies to carefully gauge their offerings and pursue consistency between the new offering's features and the dynamics of its established brand equity characteristics. A bubble developed without checking this consistency can undermine the development of brand equity over the course of time, and hence any future ability to manage market instability.

Companies that are not characterized by strong brand identity are in the opposite situation. Despite having to surmount serious obstacles in developing a sizable bubble (due to being less well known and having less potential to affirm the distinctive features of their offering), they are much freer in formulating offerings, as they are not constrained by the need to preserve well-defined brand equity. In these cases, very significant results can be obtained over the short term, for example with a truly innovative and well-promoted offering. However, the strategic and operational capacity of a company emerge over the long term, in the continuous, progressive development of demand bubbles, where the result is not ensured by a random, profitable offering, but by planned, managed action over market instability.

Hence it is not enough to have developed a solid brand relationship. A company needs to have developed a matrix of relationships with the logistics, supply/distribution and financing organisations needed to maintain the ongoing design of bubbles over time. It is precisely these relationships that allow companies operating in inter-dependent markets to have access to the resources needed for the development of demand bubbles.

Access to financial resources is ensured by stable relationships with financing organisations and allows a company to focus significant promotional activities at very short notice for ongoing brand equity affirmation and management. The planning of manufacturing, logistics and marketing activities also absorbs sizable financial resources, especially because bubble success depends on the flexible management of product manufacturing and distribution so as to make products easy to find. The manufacturing/supply/logistics relationships are themselves crucial variables in the design and implementation of demand bubbles. Therefore, manufacturing and distribution companies must be able to intertwine with upstream and downstream organisations in co-maker relationships that allow for the activation of bubbles. Of relevance to this end is the flow of products from manufacturing to distribution, and the processes controlling the flow of information to and from the market.

In order to identify and turn the demand bubbles that companies need into reality, the timely gathering of market information is needed first of all, and then the ability to communicate to the market regarding the introduction and of market offerings. For the introduction and promotion of the offering, it is crucial that companies have preferential access to media and the potential to instigate communication activities at points of sale. Therefore, it is also true in this case that it is a question of having established prior working relationships with the parties directly involved in the market information transmission process. Preferential 
access (concerning both time and costs) to information channels represents a fundamental condition for the development of demand bubbles, and presupposes a comfortable relationship with the world of communication. This is what usually happens with companies endowed with significant brand equity - the result of continuous, targeted investment.

Regarding information gathering, the availability of an effective company information system is a necessary precondition to designing and managing demand bubbles. In particular, the information system must be able to gather large quantities of data and extract specific indicators suitable for identifying relevant trends that can be used to manage market instability. Besides intelligence techniques ${ }^{11}$, which concern the gathering of information, sophisticated data processing techniques also become useful - such as data mining techniques ${ }^{12}$, designed to search for relationships between data that cannot always be predicted by analysts.

The traditional approach to market surveys is based on the examination of representative samples of the population under study. It cannot be applied extensively to unstable markets because the time required for research design, data gathering and processing is too long and the market data access method is rendered obsolete. The information retrieved is too expensive and uncertain with respect to developments in unstable markets. Therefore, in this context, relationships with key market players have a central role in the process of data gathering and processing. Companies must gather information directly from the market (both supply and demand) and acquire the potential to access distribution directly. This is the case for the automotive industry, where the role played by market information is so key that some car makers (e.g. Mercedes) have focused the business on getting closer to demand - in search of a superior position from which to acquire information on customer satisfaction. As a consequence, the parent companydealer relationship developed according to a concept of risk sharing. Another example is Benetton, where the franchised stores have participated in an ongoing, reliable information exchange process for a long time ${ }^{13}$. However, the company also opened its own stores thereby ensuring direct access to the market. To this end, for example, research conducted via the Internet is growing in importance, as it allows for fast response times at low cost, and at the same time enables the follow-up of the analysis targets ${ }^{14}$ more completely compared to other analysis methods.

Managing market instability through the creation and management of demand bubbles therefore requires the development of specific relationships between the companies and the various 'players' in the market. A crucial role is played by the system of relationships with final demand, expressed by the concept of brand. At the same time, there are relationships established with distributors, media, logistics and financing organisations. As mentioned above, the development and management of these relationships requires specific, intense activity aimed at this precise goal, made possible by a sophisticated complex of intangible resources (brand equity, information systems and corporate culture).

Indeed these resources, which concern 'the total knowledge accumulated by the company plus an array of channels that allow for the gathering of information relevant to the company, ${ }^{15}$, are characterized by the twofold nature of input and output. Input: intangible resources enable companies to acquire information and knowledge that is later processed and systematized through specifically designed 
processes. Such input data flow is indeed controlled by a specifically designed and implemented range of activities.

The potential output instead includes those actions - based on the information gathered and processed by the company - that create a system of relationships with the environment, continuously operating and feeding on the input-output circuit. Hence the information and knowledge acquisition system that allows for the development of a relationship management ability (information system) is in turn determined by the resources operating more specifically in the output sector. That is, the reality of a specific offering and company identity (brand equity and corporate culture) is that the essential elements and external manifestation of them are acquired through the information system.

Therefore, the ability of a company to manage market instability through demand bubbles requires a complex and sizable system of intangible resources, which can in turn derive from long competitive experience in markets characterized by oversupply. Indeed, the intangible resources mentioned above require the following in order to evolve over time: specific investments aimed precisely at this goal and time for development. They cannot simply be acquired as they cannot be extrapolated from the context in which (and for which) they have been developed and then inserted into different resource contexts ${ }^{16}$.

The ability to create and manage demand bubbles, therefore, flows from a company's complex competitive ability, and only organizations strongly oriented toward the development of a significant system of intangible resources can be considered really able to manage market instability.

\section{Bibliography}

Bigus Joseph, Data Mining with Neural Networks, McGraw Hill, New York, 1996.

Brondoni Silvio M. (ed.), Marketing Lexicon, CLUEB, Bologna, 2000.

Brondoni Silvio M, 'Comunicazione, risorse invisibili e strategia competitiva d'impresa', Sinergie, n. 43-44, 1997.

Brondoni Silvio M., Brand Policy and Brand Equity, Symphonya. Emerging Issues in Management (symphonya.unimib.it), n. 1, 2000-2001. http://dx.doi.org/10.4468/2001.1.02brondoni

Brondoni Silvio M., Frammentazione della domanda e innovazione di offerta nei mercati globali, Manager \& Impresa, Il Sole 24 Ore, Monday, November 5, 2001.

Brondoni Silvio M., La frammentazione apre la via del successo, Manager \& Impresa, Il Sole 24 Ore, Monday, November 5, 2001, p. 40.

Chamberlin Edward H., Teoria della concorrenza monopolistica, La Nuova Italia, Florence, 1961, The Theory of Monopolistic Competition, VII ed., Harvard University Press, Cambridge, Mass. 1960.

Corniani Margherita, Agenzia di pubblicità e 'brand custodianship', in Sinergie, no. 43-44, 1997.

Corniani Margherita, Sistema informativo aziendale e dinamiche competitive, Giappichelli, Turin, 2000 .

Day George S., 'Learning About Markets', R. Deshpandé (ed.), Using Market Knowledge, Sage Publications, Thousand Oaks, Ca, 2001, pp. 9-29.

Del Ciello Nicola, Dulli Susi, Saccardi Alberto, Metodi di data mining per il customer relationship management, Franco Angeli, Milan, 2000. 
Deshpandé Rohit (ed.), Developing a Market Orientation, Sage Publications, Thousand Oaks, Ca, 1999.

Deshpandé Rohit (ed.), Using Market Knowledge, Sage Publications, Thousand Oaks, Ca, 2001.

Di Gregorio Angelo, La valutazione della strategia, UTET, Turin, 1996.

Dibb Sally, Simkin Lyndon, The Market Segmentation Workbook, Routledge, London, 1996.

Evrard Yves, Pras Bernard, Rousx Elyette, Market. Etudes et recherches en marketing, Nathan, Paris, 1997.

Gustafson Anders, Herrmann Andreas, Huber Frank (eds.), Conjoint Measurement. Methods and Applications, Springer, Berlin, 2000.

Kotler Philip, Armstrong Gary, Saunders John, Wong Veronica, Principles of Marketing, Prentice Hall Europe, London, 1999.

Lambin Jean-Jacques, Chumpitaz Rubén, Market-Orientation and Corporate Performance, Symphonya. Emerging Issues in Management (symphonya.unimib.it), n. 2, 2000-2001. http://dx.doi.org/10.4468/2001.2.03lambin.chumpitaz

Lambin Jean-Jacques, Market-Driven Management, McMillan, London, 2000.

Lambin Jean-Jacques, Marketing strategico e operativo, McGraw-Hill, Milan, 2000.

Mc Donald Malcolm, Dunbar Ian, Market Segmentation, MacMillan Business, London, 1995.

Prescott John, Miller Stephen H. (eds.), Proven Strategies in Competitive Intelligence. Lessons from the Trenches, John Wiley and Sons, New York, NY, 2001.

http://dx.doi.org/10.1002/cir.1013

Trout Jack, Rivkin Steve, Differentiate or Die, John Wiley and Sons, New York, 2000.

Van Raaij W. Fred, Stroeker Natasha E., The Marketing Concept And Market Segmentation, Working Paper, Management Report n. 9-13, Erasmus Universiteit Rotterdam, March; published in G. Fennel e J. Saegert (eds.), Taking the Marketing Concept Seriously, Sage Publications, Thousand Oaks, Ca, 1997.

\section{Notes}

${ }^{1}$ See A. Di Gregorio, La valutazione della strategia, UTET, Turin, 1996, Chap. I.

${ }^{2}$ See S.M. Brondoni, A. Di Gregorio, Brand Equity e politica di marca, Progetto Comunicazione Aziendale, Rapporto di Ricerca no. 2/94, CREA - Centro di Ricerche Economico Aziendali, Università Bocconi, DEPA - Dipartimento di Economia Politica e Aziendale, University of Milan, January 1995; S.M. Brondoni, Brand Policy and Brand Equity, Symphonya. Emerging Issues in Management (symphonya.unimib.it), n. 1, 2000-2001.

3 See S.M. Brondoni, M. Gatti, M. Corniani, Competizione globale, risorse immateriali $e$ responsabilità sociale d'impresa, in Atti del Convegno AIDEA, Novara, 4-5 October 2002.

${ }^{4}$ See E. Valdani, Definizione e segmentazione del mercato, Giuffré, Milan, 1984.

5 See S.M. Brondoni, M. Gatti, M. Corniani, Competizione globale, risorse immateriali $e$ responsabilità sociale d'impresa, in Atti del Convegno AIDEA, Novara, 4-5 October 2002.

${ }^{6}$ See Comunicazione, risorse invisibili e strategia competitive d'impresa, in Sinergie, no. 43-44, 1997.

7 See S.M. Brondoni, Brand Policy and Brand Equity, Symphonya. Emerging Issues in Management (symphonya.unimib.it), n. 1, 2000-2001; S.M. Brondoni, 'Time Compression And Time Value As A Competitive Strategy', in G. Morello (ed.) Time and Management, Part Three, Collana di Studi e Ricerche ISIDA, Palermo, Proceedings of the Conference held in Palermo, April 6-8, 2001.

${ }^{8}$ See J.J. Lambin, Marketing strategico e operativo, McGraw-Hill, Milan, 2000. 
9 See Chamberlain Edward H., Teoria della concorrenza monopolistica, La Nuova Italia, Florence, 1961.

${ }^{10}$ See M. Corniani, Agenzia di pubblicità e 'brand custodianship', Sinergie, n. 43-44, 1997.

${ }^{11}$ Intelligence can be defined as the planned, continuous carrying out of research using formal and informal information sources to allow for the monitoring of aspects deemed essential for the business and which, of course, are not already available within the company or derived from market or marketing surveys. The object of intelligence analysis is typically the environment outside the company, technology, $\mathrm{R} \& \mathrm{D}$, financial markets and generally in relation to action by major competitors. See M. Corniani, Sistema informativo aziendale e dinamiche competitive, Giappichelli, Turin, 2000.

${ }^{12}$ Data mining identifies processes for the coding, processing and selection of data based on the application of sophisticated algorithms to large quantities of data, with the purpose of identifying non-trivial relationships within the data that are not pre-determined or pre-requested by decision makers.

${ }^{13}$ Benetton was one of the first companies to activate dedicated communication lines between the parent company, subsidiaries and retail points around the world, thereby allowing for the fast, frequent and reliable return of information from the market.

${ }^{14}$ Consider, for example, the potential tracking of Internet surfers, made possible by specific technological applications, which produces knowledge of the path followed by someone connected to the net.

${ }^{15}$ See H. Itami, Le risorse invisibili, ISEDI Petrini, Turin, 1988, p. 43.

16 See S.M. Brondoni, M. Gatti, M. Corniani, Competizione globale, risorse immateriali $e$ responsabilità sociale d'impresa, in Atti del Convegno AIDEA, Novara, 4-5 October 2002. 